\title{
Improvement in sodium cromoglycate delivery from a spacer device by use of an antistatic lining, immediate inhalation, and avoiding multiple actuations of drug
}

\author{
C O’Callaghan, J Lynch, M Cant, C Robertson
}

\begin{abstract}
Background-Aerosols generated from metered dose inhalers may be highly charged. The aim of this study was to determine whether lining the walls of a polycarbonate spacer device with an antistatic agent would result in an increase in drug output. The effects of multiple actuations of drug into the spacer device and increasing residence time of drug within the spacer were also determined.

Methods-The amount of sodium cromoglycate contained in particles of various size available for inhalation (per $5 \mathrm{mg}$ actuation) from a $750 \mathrm{ml}$ polycarbonate spacer was determined by impinger measurement and spectrophotometric assay. Results-Lining the spacer with an antistatic agent increased the mean (SD) amount of sodium cromoglycate in particles $<5 \mu \mathrm{m}$ available for inhalation (per $5 \mathrm{mg}$ actuation) by $244 \%$ from $(0.59(0.03)$ to $1.44(0.2) \mathrm{mg})$. When there was a 20 second interval between actuation into the spacer device and inhalation, sodium cromoglycate available for inhalation in particles $<5 \mu \mathrm{g}$ decreased by $67 \%$ (from 0.59 $(0.03) \mathrm{mg}$ to $0.2(0.01) \mathrm{mg})$. Use of the spacer device increased sodium cromoglycate available for inhalation in respirable particles $(<5 \mu \mathrm{m})$ by $18 \%$ compared with direct delivery by metered dose inhaler. Multiple actuations into the spacer decreased the amount of sodium cromoglycate available for inhalation in particles $<5 \mu \mathrm{m}$ by $31 \%$ after two actuations and $56 \%$ after three acutations. Conclusions-Multiple actuations of sodium cromoglycate into a spacer device before inhalation should be avoided, and inhalation from spacer devices should take place immediately after actuation to ensure maximum dose. Lining of a standard spacer device with an antistatic agent significantly increased output of sodium cromoglycate. This may have implications for improved therapeutic response and drug cost.
\end{abstract}

(Thorax 1993;48:603-606)

To combat the problems of high oral deposition and coordination difficulties associated with pressurised inhalers, ${ }^{1}$ many companies have designed and developed spacer devices.
The key features of a spacer device are a chamber or reservoir where the discharged aerosol cloud can be held, and a one way demand valve which allows air to be drawn through the chamber on inspiration but prevents air passing through the chamber on expiration. These devices may be modified by adding a face mask to allow use by preschool children as an alternative to nebulisation. ${ }^{2}$

Comparative studies between sodium cromoglycate $1 \mathrm{mg}$ and $5 \mathrm{mg}$ metered dose inhalers have confirmed that the $5 \mathrm{mg}$ inhaler is clinically more effective and has a longer duration of action. Knowledge of the dose of sodium cromoglycate available for patients to inhale therefore appears to be important. A polycarbonate large volume spacer device has been developed (Fisonair; Fisons Ltd) for the delivery of sodium cromoglycate. Little is known about the output of sodium cromoglycate $(5 \mathrm{mg}$ ) from this device, however, or how best to use it. For example, aerosol particles generated from a metered dose inhaler are highly charged and may be attracted electrostatically to the polycarbonate walls of the spacer device, decreasing the amount of drug available for inhalation.

In addition, many patients prescribed two actuations of sodium cromoglycate via a spacer device will actuate twice into the device and then inhale as this is more convenient. Mothers of young children often actuate drug into a spacer device and allow several seconds to elapse before they can coax their child to breathe adequately from the device. The effect of these techniques on drug output is not known.

The purpose of this study was to determine: (1) whether lining internal walls of a spacer device with an antistatic agent would reduce electrostatic deposition of particles and thus increase the dose available to patients for inhalation; (2) the effect on the therapeutic dose of delivering multiple actuations of sodium cromoglycate $(5 \mathrm{mg}$ per actuation) into the spacer device before inhaling the aerosol cloud; (3) the effect on the available therapeutic dose of the time the drug resides in the spacer device before inhalation.

\section{Methods}

A multistage liquid impinger ${ }^{3}$ was used to assess the aerodynamic particle size distribution of the aerosolised clouds. The device consists of a throat that contains a right 
angled bend (to simulate the oropharynx) and four impaction stages. Stages 1, 2, and 3 consist of impaction jets together with sintered glass collecting discs. The fourth stage consists of a narrow jet aimed at the base of the collection chamber.

The impinger had been calibrated by sampling an aerosol of dibutyl phthalate droplets that had been sized by a Malvern laser device (Malvern 3600; Malvern Ltd). A 50\% cutoff diameter was derived for each stage of the device and was expressed in terms of aerodynamic diameter. The aerodynamic diameter of a droplet is the diameter of a unit density spherical particle with the same settling velocity as the droplet in question.

\section{TEST METHOD}

Initially a standard metered dose inhaler of sodium cromoglycate $(5 \mathrm{mg})$ was assessed. The mouthpiece of the metered dose inhaler was connected to the impinger with a small rubber sock and air was drawn through the apparatus at a flow rate of $60 \mathrm{l} / \mathrm{min}$. The aerosol was then discharged through the impinger. This was repeated on four occasions to facilitate the chemical assay procedures. The metered dose inhaler was shaken between each actuation. Each experiment was repeated on four occasions.

For the Fisonair spacer device the aerosol was discharged into the device and, after a delay of about one second, the mouthpiece of the Fisonair spacer was connected to the impinger and the aerosol drawn from the spacer. Again the test flow rate was $60 \mathrm{l} / \mathrm{min}$ and the procedure was repeated on four occasions to facilitate the chemical assay procedure. This allowed comparison of the dose delivered from the Fisonair with that delivered from a standard adaptor.

The first actuation from the metered dose inhaler was discarded for each experiment and no more than 20 actuations were used from the same inhaler. The time interval between actuations was 10-15 seconds.

\section{Effect of antistatic agent on drug delivery}

The inner walls of the Fisonair spacer device were lined with a thin film of a commercially available antistatic spray (Antistat) and left for 24 hours. As before the aerosol was discharged into the spacer device and, after a delay of one second, it was drawn from the device into the impinger. Again the test flow rate was $60 \mathrm{l} / \mathrm{min}$ and the procedure was repeated on five occasions. The effect of the antistatic lining on residence time was also studied. The aerosol was discharged into the spacer device lined with antistatic and left for 20 seconds before the spacer was emptied via the impinger. This experiment was repeated on four occasions.

\section{Multiple dosing}

To investigate the effect of multiple actuations into the Fisonair without an antistatic lining before inhalation by the patient the following study was conducted. Sodium cromoglycate was discharged into the spacer after which the standard adaptor was shaken and sodium cromoglycate was fired into the spacer. One second later the device was connected to the impinger and the aerosol drawn from the device. The dose available to the patient after two actuations into the device could therefore be assessed. This was repeated with three actuations of sodium cromoglycate $(5 \mathrm{mg})$. Each experiment was repeated on four occasions.

\section{Effect of residence time delay}

The residence time is the period between actuation of the metered dose inhaler into the spacer device and connection to the multistage liquid impinger. To investigate the effective residence time on output from the Fisonair, residence times of $1,5,10$, and 20 seconds were examined. For example, one actuation was placed in the Fisonair and five seconds later the drug was sucked from the Fisonair through the impinger. This was repeated on five occasions to facilitate chemical assay procedures. Each experiment was repeated on four occasions for the residence times chosen.

\section{Drug assay}

After the drug had been drawn into the impinger the various stages were washed out with dihydrochlorofluoromethane and distilled water. The washings were filtered and the sodium cromoglycate crystals collected. Filters were washed quantitatively into 100 $\mathrm{ml}$ volumetric flasks. Dihydrochlorofluoromethane washes surfactant from the drug particles. Anhydrous sodium cromoglycate was assayed spectrophotometrically with a wavelength of $356 \mathrm{~nm}$. The spectrophotometer had previously been calibrated with solutions of known concentrations of sodium cromoglycate. The absorbance for a $1 \%$ solution using a $1 \mathrm{~cm}$ silica cuvette was measured as 166 units.

With the data acquired from the multistage impinger, together with the $50 \%$ cutoff diameter for each stage of the device, a plot of aerodynamic size against cumulative percentage undersize was constructed. From this graph the following measurements were calculated: (1) mass median aerodynamic diameter (MMAD) which is the diameter of a droplet such that half of the aerosol mass was contained in smaller droplets and half in larger droplets; (2) geometric standard deviation (GSD) (ratio of the $84.1 \%$ diameter to $50 \%$ of the MMAD) which is a measure of the width of the droplet distribution; (3) the amount of drug contained in particles $<3 \mu \mathrm{m}$ and $<5 \mu \mathrm{m}$ in diameter.

After each study the spacer device and actuator were also washed out to collect any sodium cromoglycate left inside. The total dose from the metered dose inhaler could therefore be determined. When an antistatic agent was used on the spacer device, spectrophotometric assay of the spacer contents was not performed.

A known concentration of sodium cromoglycate was measured spectrophotometrically 
Effect of delivery methods of sodium cromoglycate on drug output.

\begin{tabular}{|c|c|c|c|c|}
\hline \multirow[b]{2}{*}{ Method of delivery of sodium cromoglycate } & \multicolumn{4}{|c|}{$\begin{array}{l}\text { Mean (SD) amount of sodium cromoglycate } \\
\text { per } 5 \mathrm{mg} \text { actuation }(\mathrm{mg})\end{array}$} \\
\hline & $\begin{array}{l}\text { In particles } \\
<5 \mu m\end{array}$ & $\begin{array}{l}\text { In particles } \\
<3 \mu m\end{array}$ & $\begin{array}{l}\text { Mean }(S D) \\
M M A D(\mu m)\end{array}$ & $\begin{array}{l}\text { Mean }(S D) \\
G S D\end{array}$ \\
\hline Directly from metered dose inhalers & $0 \cdot 5(0 \cdot 06)$ & $0 \cdot 19(0 \cdot 02)$ & $10 \cdot 5(0 \cdot 05)$ & $1.9(0.004)$ \\
\hline $\begin{array}{l}\text { Via Fisonair spacer device } \\
\text { Effect of multiple actuations } \\
\text { One actuation before inhalation } \\
\text { Two actuations before inhalation } \\
\text { Three actuations before inhalation }\end{array}$ & $\begin{array}{l}0.59(0.03) \\
0.41(0.03) \\
0.26(0.02)\end{array}$ & $\begin{array}{l}0 \cdot 24(0.03) \\
0 \cdot 21(0 \cdot 02) \\
0 \cdot 1(0.01)\end{array}$ & $\begin{array}{l}5 \cdot 3(0 \cdot 04) \\
5 \cdot 48(0 \cdot 09) \\
5 \cdot 65(0 \cdot 15)\end{array}$ & $\begin{array}{l}1.9(0.04) \\
1.93(0.01) \\
1.84(0.03)\end{array}$ \\
\hline $\begin{array}{l}\text { Effect of residence time } \\
\text { No time delay before inhalation } \\
5 \text { second delay before inhalation } \\
10 \text { second delay before inhalation } \\
20 \text { second delay before inhalation }\end{array}$ & $\begin{array}{l}0.59(0.03) \\
0.48(0.06) \\
0.23(0.02) \\
0.2(0.01)\end{array}$ & $\begin{array}{l}0 \cdot 24(0.01) \\
0 \cdot 22(0.03) \\
0 \cdot 18(0.01) \\
0 \cdot 11(0.01)\end{array}$ & $\begin{array}{l}5 \cdot 3(0 \cdot 04) \\
4 \cdot 93(0 \cdot 04) \\
3 \cdot 75(0 \cdot 1) \\
4 \cdot 7(0 \cdot 18)\end{array}$ & $\begin{array}{l}1.9(0.04) \\
1.92(0.06) \\
2 \cdot 9(0.08) \\
2 \cdot 17(0.01)\end{array}$ \\
\hline $\begin{array}{l}\text { Effect of antistatic lining } \\
\text { No time delay before inhalation } \\
20 \text { second delay before inhalation }\end{array}$ & $\begin{array}{l}1 \cdot 44(0 \cdot 2) \\
0 \cdot 52(0.04)\end{array}$ & $\begin{array}{l}0 \cdot 6(0 \cdot 15) \\
0 \cdot 24(0 \cdot 03)\end{array}$ & $\begin{array}{l}5 \cdot 23(0 \cdot 09) \\
5 \cdot 25(0 \cdot 23)\end{array}$ & $\begin{array}{l}1.88(0.06) \\
1.88(0.12)\end{array}$ \\
\hline
\end{tabular}

MMAD - mass median aerodynamic diameter; GSD—geometric standard deviation.

on several occasions to determine the coefficient of variation of the assay. Humidity and temperature were measured during the study period.

\section{Results}

Lining the spacer with an antistatic agent increased output of sodium cromoglycate to give a $288 \%$ and $315 \%$ increase in the amount of drug available to the patient in particles $<5 \mu \mathrm{m}$ and $<3 \mu \mathrm{m}$ diameter respectively compared with drug delivered directly from the metred dose inhaler. Compared with the same spacer without an antistatic lining this represents a $244 \%$ and $250 \%$ increase in drug output of particles $<5 \mu \mathrm{m}$ and $<3 \mu \mathrm{m}$, respectively (table, fig 1 ).

Sodium cromoglycate recovered from the spacer device decreased with increasing residence time (table, fig 2). A 20 second residence time resulted in a fall in sodium cromoglycate of $67 \%$ and $55 \%$ in particles $<5 \mu \mathrm{m}$ and $<3 \mu \mathrm{m}$, respectively. When an antistatic agent was used to line the spacer the amount of sodium cromoglycate available

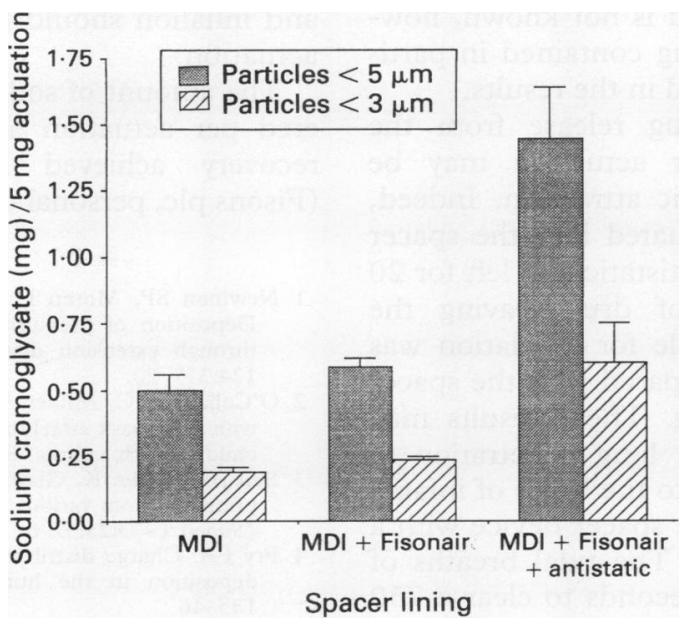

Figure 1 Mean (SD) amount of sodium cromoglycate contained in particles $<5 \mu \mathrm{m}$ and $<3 \mu \mathrm{m}$ available to the patient when delivered by metered dose inhaler (MDI) alone, via the Fisonair spacer device, or via the Fisonair with an antistatic lining. for inhalation after a 20 second residence time was increased (table). Compared with a drug residence time of 20 seconds in a spacer device without an antistatic lining there was a $260 \%$ and $218 \%$ increase in sodium cromoglycate released in particles $<5 \mu \mathrm{m}$ and $<3 \mu \mathrm{m}$, respectively (fig 2 ).

The mean (SD) MMAD and GSD of the aerosol cloud discharged directly from the metered dose inhaler or via the spacer device are shown in the table. Use of the spacer increased the amount of sodium cromoglycate available for inhalation by a mean of $18 \%$ (in particles $<5 \mu \mathrm{m}$ ) and $26 \%$ (in particles $<3 \mu \mathrm{m}$ ) compared with delivery directly from the metered dose inhaler (fig 1).

Multiple actuations into the spacer decreased the amount of drug available per actuation (table). There was a fall of sodium cromoglycate in particles $<5 \mu \mathrm{m}$ of $31 \%$ per actuation after two actuations, and $56 \%$ per actuation after three actuations (fig 3 ).

The mean (SD) recovery of sodium cromoglycate per $5 \mathrm{mg}$ shot was $4.7(0.27) \mathrm{mg}$. The coefficient of variation for the assay of sodium cromoglycate was $2 \cdot 5 \%$. The mean

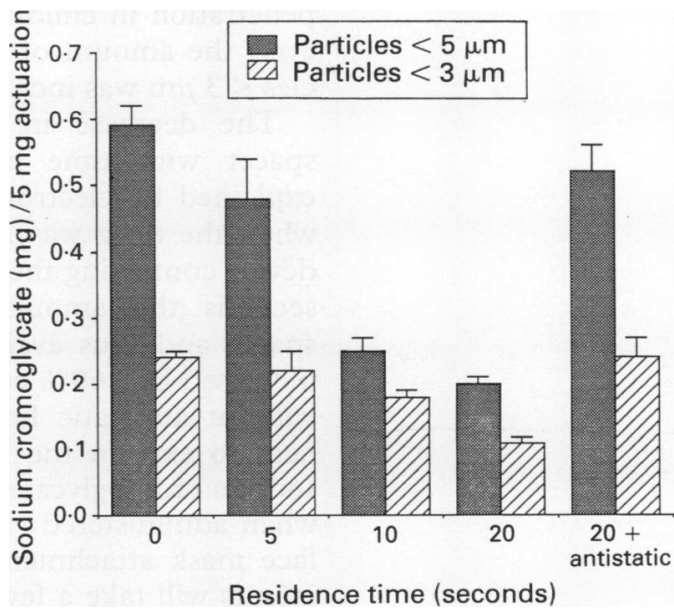

Figure 2 Mean (SD) amount of sodium cromoglycate available to the patient in particles $<5 \mu \mathrm{m}$ and $<3 \mu \mathrm{m}$ per $5 \mathrm{mg}$ actuation following various lengths of residence time within the spacer. The amount of sodium cromoglycate available at 20 seconds when the spacer was lined with an antistatic agent is also shown. 
Figure 3 Effect of multiple actuations into the standard unlined polycarbonate spacer device on mean (SD) amount of drug available per actuation contained in particles $<5 \mu \mathrm{m}$ and $<3 \mu \mathrm{m}$.

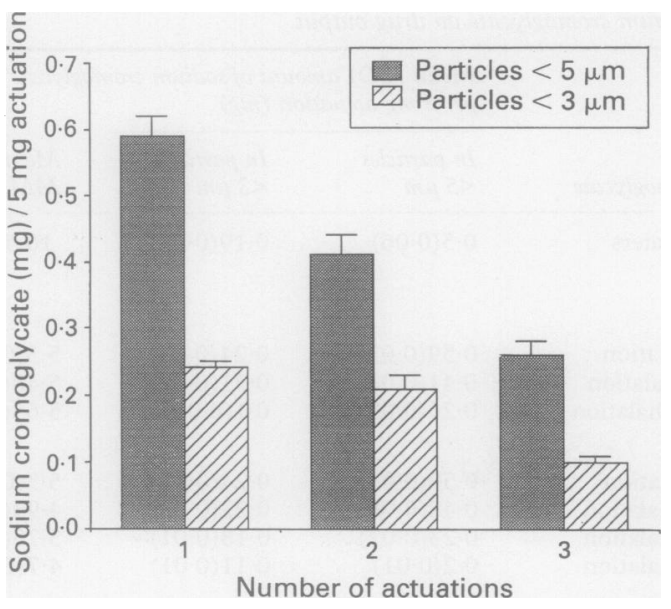

(SD) humidity over the study period was $55(3) \%$ and the mean (SD) temperature of the room over the study period was $23(2)^{\circ} \mathrm{C}$.

\section{Discussion}

Aerosols produced by atomisation are often highly charged to an extent which is not likely to occur naturally. ${ }^{4}$ Increased particle deposition on surfaces as a result of electric charges on aerosol particles is recognised. The placing of a unipolar electric charge on particles has been found to increase the deposition in the respiratory tract. ${ }^{5}$ In a study of penetration of particles through the human nose Pattle $^{6}$ found that $10-30 \%$ of the mass of particles of mass median diameter $0.05-0.4 \mu \mathrm{m}$ was deposited. He suggested this deposition may be due to electrostatic charges carried by these particles.

We hypothesised that the polycarbonate surface of the spacer device may enhance electrostatic attraction and deposition of drug on the spacer walls. This was confirmed. Use of an antistatic spray increased the drug contained in respirable particles $(<5 \mu \mathrm{m})$ leaving the spacer by $244 \%$. The ideal particle size for inhalation of drugs is often quoted as $<5 \mu \mathrm{m}$. As the ideal size of particles for lung penetration in childhood is not known, however, the amount of drug contained in particles $<3 \mu \mathrm{m}$ was included in the results.

The decrease in drug release from the spacer with time after actuation may be explained by electrostatic attraction. Indeed, when the drug was actuated into the spacer device containing the antistatic and left for 20 seconds the amount of drug leaving the spacer and thus available for inhalation was increased by $260 \%$ compared with the spacer without antistatic lining. These results may help to explain the low lung penetration of sodium cromoglycate into the lungs of infants when administered via a spacer device with a face mask attachment. ${ }^{7}$ The tidal breaths of infants will take a few seconds to clear a 750 $\mathrm{ml}$ spacer of aerosol during which time the amount of drug available is falling rapidly.

We feel that the use of an antistatic lining for spacer devices will considerably increase drug availability to patients. This has immense implications with regard to clinical benefit from enhanced deposition and also to the cost of treatment. For example, the $5 \mathrm{mg}$ sodium cromoglycate inhaler is advised to be given in a dose of two actuations twice daily. With the spacer device lined with an antistatic agent only one actuation twice daily may be needed. The antistatic spray in the study should not be used for patients as toxicity may be a problem. Non-toxic antistatic agents suitable for patient use are now available and are under evaluation. It is not possible to say if other drugs will be affected in a similar way. Each drug and alteration of spacer lining will require individual testing.

Actuation of sodium cromoglycate $5 \mathrm{mg}$ inhalers directly into a standard polycarbonate $750 \mathrm{ml}$ spacer device resulted in an $18 \%$ increase in dose delivered in the respirable range $(<5 \mu \mathrm{m})$ compared with direct actuation from a metered dose inhaler. In practice this would mean higher lung deposition of sodium cromoglycate. The greater length of the spacer device compared with the throat results in less impaction of the rapidly moving aerosol.

In paediatric practice it is common for parents and patients to place multiple actuations into the spacer device and then inhale for convenience. Experiments with multiple actuations of sodium cromoglycate $(5 \mathrm{mg}$ ) into a spacer have shown that there is a substantial decrease in drug released in particles of $<5 \mu$ m diameter compared with a single dose delivered from the same device. This may be due in part to a rapid increase in pressure within the spacer with actuations forcing drug from previous actuations on to the wall. In addition, collisions between aerosol particles may be important. The possibility of collision with agglomeration of particles may be reflected by the slight increase of particle size (MMAD) with multiple actuations.

To ensure maximum dosage we found that inhalation from the spacer should take place as soon as possible after actuation. The dose in respirable particles $(<5 \mu \mathrm{m})$ decreased to less than $50 \%$ within 10 seconds of actuation. Subsequent studies with other antiasthma aerosols and spacer devices (unpublished results) support our findings that multiple actuations into the spacer should be avoided and inhalion should follow immediately after actuation.

The amount of sodium cromoglycate recovered per actuation agrees closely with drug recovery achieved by the manufacturers (Fisons plc, personal communication).

1 Newman SP, Moren F, Pavia D, Little F, Clarke SW Deposition of pressurised suspension aerosols inhaled through extension devices. Am Rev Respir Dis 1981; 124:317-20.

2 O'Callaghan C, Milner AD, Swarbrick A. Spacer device with face mask attachment for giving bronchodilators to children with asthma. BMF 1989;298:160-1.

3 Bell JH, Brown K, Glasby J. Variation in delivery of isoprenaline from various pressurised inhalers. $\mathcal{f}$ Pharmacol (Suppl) 1973;25:32-6.

4 Fry FA. Charge distribution on polystyrene aerosols and deposition in the human nose. Aerosol Sci 1970;1: 135-46.

5 Melandri C, Prodi V, Tarroni G, Formigani de Zaiacomo $T$, Bonpane GF, Maestri G. On the deposition of unipolarly charged particles in the human respiratory tract. In: Walton WH, ed. Inhaled particles. No. 4. Oxford: Pergamon, 1977:193-201.

6 Pattle RG. The retention of gases and particles in the human nose. In: Davies $\mathrm{CN}$, ed. Inhaled particle and vapours. Oxford: Pergamon, 1961:302-12.

7 Salmon B, Wilson NM, Silverman M. How much aerosol reaches the lungs of wheezy infants and toddlers? Arch Dis Child 1990;65:401-3. 